\title{
Rancang Bangun Mesin CNC (Computer Numerical Control) Laser dengan Metode Design for Assembly
}

\author{
Andre Muchlis \\ Prodi Teknik elektro \\ Universitas Negeri Gorotalo \\ Gorontalo, Indonesia \\ andremuchlis1@gmail.com
}

\author{
Wrastawa Ridwan \\ Prodi Teknik elektro \\ Universitas Negeri Gorotalo \\ Gorontalo, Indonesia \\ wridwan@ung.ac.id
}

\author{
Iskandar Z. Nasibu \\ Prodi Teknik elektro \\ Universitas Negeri Gorotalo \\ Gorontalo, Indonesia \\ zul.nasibu@ung.ac.id
}

\begin{tabular}{ll}
\hline Diterima & : Januari 2021 \\
Disetujui & : Januari 2021 \\
Dipublikasi & : Januari 2021 \\
\hline
\end{tabular}

Abstrak-CNC Laser (Computer Numerical Control) adalah alat yang memiliki fungsi untuk mengukir/mencetak berbagai tulisan dan kaliqrafi secara otomatis berdasarkan media yang digunakan seperti Acrilic, Fiber, Almunium, dan kayu. Perancangan $\mathrm{CNC}$ laser menggunakan metode Design For Assembly Boothroyd (DFA), G-Code, dan Closed Loop System (Loop Tertutup). Kelebihan metode DFA yaitu mengestimasikan pengurangan waktu perakitan. Metode $G$ Code lebih ke menyatukan gerakan yang akan di lakukan mesin, seperti bergeser ke titik A, titik B. Kemudian pada metode Closed Loop System (Loop Tertutup) bekerja mengirim sinyal umpan balik ke pengendali untuk mengecilkan kesalahan sistem. Hasil pengujian dari komponen pada masing-masing alat secara keseluruhan berupa input dan output menjadi kesatuan alat mesin $C N C$ laser cutting dan engraver. Software GRBL dihubungkan pada $C N C$ shild. GRBL mengirim $G$-Code ke arduino dan menerjemahkan isi dari $G$ Code satu persatu untuk menghasilkan pergerakan motor stepper dan cahaya laser. Telah didapatkan sistem pengontrolan mesin laser engravir yang bisa menggerakkan mesin kearah dua sumbu $X$ dan $Y$, yang tersusun dari beberapa komponen yaitu komputer, kontroler arduino nano, motor stepper, laser module, power supplay dan emergency stop. Pengujian laser engraver dilakukan dengan medium plywood dan berbagai pola gambar. Hasil pengujian menunjukkan alat dapat bekerja sesuai dengan pola gambar yang ada.

Kata Kunci- CNC laser, Design For Assembly, Arduino.

Abstract - CNC Laser (Computer Numerical Control) tools that have a function to automatically engrave / print various writings and kaliqrafi based on the media used such as Acrilic, Fiber, Aluminum, and wood. CNC laser design uses the Design For Assembly Boothroyd (DFA), G-Code, and Closed Loop System (Closed Loop) method. The advantage of the DFA method is that it estimates the reduced assembly time. The G-Code method is more about unifying the movements that the machine will do, such as moving from point $A$ to point $B$. Then the Closed Loop System method works to send a feedback signal to the controller to minimize system errors. The test results of the components on each tool as a whole are in the form of input and output into a unity of the CNC laser cutting and engraver machine tool. GRBL software is linked to the CNC shild. The GRBL sends the G-Code to the Arduino and translates the contents of the G-Code one by one to produce stepper motor movement and laser light. A schematic of a laser engraving machine control system that is able to move the machine towards two axes $X$ and $Y$, which is composed of several components, namely a computer, Arduino nano controller, stepper motor, laser module, power supply and emergency stop. Laser engraver testing was carried out using plywood and various image patterns. The test results show that the tool can work in accordance with existing image patterns.

Keywords - CNC laser, Design For Assembly, Arduino

\section{Pendahuluan}

Mesin $C N C$ mempunyai komputer yang bisa mengubah karakter $G$-Code ke Bahasa yang bisa dikenal oleh mesin kemudian di proses dan di kirim kepada masing-masing driver motor stepper, driver laser Avoid 15 watt, dalam bentuk sinyal digital ataupun analog.CNC Engraver menggunakan Closed Loop sistem. Apabila ada kesalahan (error) pada mesin $C N C$ baik dari pengguna ataupun dari sistem elektronikanya mesin tersebut akan berhenti. Sistem kontrol numerik $C N C$ dapat berjalan karena ada perangkat komponen sistem kontrol yang mendukung operasional mesin seperti motor stepper, driver motor, breakout board control, dan power supply, serta pengontrolan dari software. Semua komponen elektronik digabungkan dengan kabelkabel sehingga membentuk perangkat CNC Engraver.

Dalam rangka menghindari atau mengurangi tingkat kesalahan tersebut, penelitian ini akan merancang sebuah alat CNC Laser (Computer Numerical Control) yang memiliki fungsi mengukir/mencetak berbagai tulisan dan kaliqrafi secara otomatis berdasarkan media yang digunakan seperti acrilic, fiber, almunium, dan kayu. Alat ini berbasis aplikasi GRBL dan LASER ENGRAVER yang berfungsi untuk mengontrol $C N C$ dengan kontrol 2 axis $\mathrm{X}$ dan $\mathrm{Y}$ untuk mengatasi segala kesulitan yang terjadi. 
Tujuan penelitian ini adalah untuk merealisasikan rancangan model pengontrolan driver motor stepper dengan laser diode dari arduino untuk karakter $G$-Code; mengetahui perancangan chasis CNC Laser dengan metode Desain For Assembly (DFA); dan untuk mengatahui gerak motor stepper yang akurat ke arah $\mathrm{X}$ dan $\mathrm{Y}$ pada mesin CNC laser.

\section{KAJIAN PUSTAKA}

Proses mesin CNC untuk pembelajaran simulasi software adalah penelitian dalam [1]. Proses mesin CNC diawali dari mendesainnya sampai dengan menghasilkan sebuah benda kerja dalam bentuk $C N C$, software simulasi $C N C$ yang digunakan, baik itu software yang mampu berdiri sendiri untuk proses kombinasi berbagai software lain sehingga mesin $C N C$ dapat berjalan menggunakan perangkat atau software komputer. Rancangan mesin $C N C$ Engraver mini yaitu sebagai alat untuk membantu para pelajar dilakukan oleh [2]. Penelitian ini bertujuan mendesain, membuat dan menguji prototipe mesin $C N C$ Engraver mini yang mampu digunakan untuk mengukir sirkuit di PCB dan ukiran artistik di kayu, akrilik dan lain sebagainya. Fokus penelitian ini pada penggunaannya untuk menguji keakurasian hasil pengerjaan milling bentuk persegi berukuran $X=20 \mathrm{~mm}, Y=15 \mathrm{~mm}$ dan $Z=2 \mathrm{~mm}$. Pengaturan perangkat keras dengan menggabungkan $G$ Code ini memberikan akurasi yang baik dan mengurangi beban kerja. G-Code mempermudah mencari informasi lokasi semua langkah motor stepper, karena status motor yang bergerak secara langsung terlihat di komputer sehingga operator dapat memulai atau menghentikan mesin kapan pun dibutuhkan.

Perancangan Sistem Multi Computer Numerical Control $(\mathrm{CNC})$ untuk plotter dan laser engraving adalah penelitian yang dilakukan oleh Diki Muhammad Sobirin [8]. Pembuatan alat ini dibuthkan 2 buah motor stepper sebagai penggerak, Axis X, dan Axis Y, motor stepper yang digunakan adalah motor stepper jenis bipolar. Motor Stepper dihubungkan pada CNC Shield yang sudah dibuat sebelumnya menggunakan Arduino uno, memiliki driver motor dan driver laser. Arduino nano digunakan untuk menkonvrensi sinyal pengontrolan laser dan motor stepper menjadi sinyal PWM untuk dapat menggerakkan servo. Perancangan dan analisis rangka mesin desktop CNC milling adalah penelitian yang dilakukan pada. Optimasi parameter CNC laser cutting pada kekasaran dan laju memotong menggunakan Taguchi Grey Relational Analysis Method adalah penelitian yang dilakukan oleh [10]. Jumlah percobaan yaitu Sembilan kali dan dilakukan tiga kali replikasi untuk bisa dapat memproses penelitian berdasarkan metode Taguchi. Kemudian pada proses optimasi dilakukan multi respon dengan menggunakan metode Grey relational analysis. Dalam proses pengambilan data yang dilakukan yaitu dapat mengukur waktu actual dengan stopwatch untuk mengetahui hasil dimensi penelitian, selanjutnya dibuat sebagai penginputan data pada laju pemotongan benda/material. Dilakukan pengujian kekasaran permukaan material dan untuk melihat hasil pemotongan sehingga nilai yang ada bisa dilihat pada permukaan benda, hasil kualitas pemotongan kekerasan permukaan bisa dipakai untuk menginput data pada nilai kekerasan. Karakter yang ada pada masing-masing nilai kekasaran, maka semakin kecil niai yang di dapat semakin baik untuk merespon laju pemotongan benda.

\section{METODE PENELITIAN}

\subsection{Design For Assembly (DFA)}

Design For Assembly (DFA) adalah desain yang memiliki pertimbangan sebuah produk untuk bisa memastikan anggaran biaya yang akan digunakan [3]. Design For Assembly (DFA) adalah sebuah rangkaian proses untuk memberikan desain prosuk sehingga memudahkan kita dalam aspek fungsional, dan untuk memudahkan perakitan komponen secara bersamaan. Design For Assembly (DFA) merupakan desain dari assembling yang nantinya akan menganalisis sebuah desain produk yang akan digunakan, desain produk pertama akan di proses sehingga kesulitan-kesulitan yang dialami oleh perakitan dapat diketahui bersama. Ini adalah prinsip yang dimiliki DFA dasar menurut Corbett, dan Dooner[4].

1. Desain produk pertama meminimal komponen variasi desain, gerakan perakitan yang dialami bisa terarah dengan sepenuhnya.

2. Desain produk kedua memiliki urutan komponen yang dapat di mengerti, mengakses untuk setiap komponen dengan mudah, komponen tetap simentris agar dapat berjalanan dengan transportasi yang diinginkan.

3. Desain produk ketiga memiliki komponen-komponen yang dapat menghalangi pandangan atau tersembunyi, dan juga komponen yang sulit di jangkau oleh perakit komponen.

4. Kemudian akan mempengaruhi bagian-bagian sebelumnya yang sudah di rakit.

5. Memungkinkan sebuah kesalahan yang akan terjadi pada perakitan.

Penjelasan lanjutan dari metode design for assembly (DFA) ini adalah tambahan peraturan dari metode DFA[5].

1. Menghilangkan jumlah komponen yang akan dirakit apabila tidak perlu digunakan.

2. Mengembangkan komponen-komponen dari atas permukaan pada bagian bawah dengan menggunakan komponen yang dirakit.

3. Produk yang sudah selesai perakitan terlebih dahulu akan di filter apabila telah memenuhi syarat, pada permukaan benda harus terlihat dan kelihatan stabil.

4. Menggunakan persyaratan metode DFA untuk memudahkan dalam pencocokan desain dan bagianbagian komponen.

5. Menggunakan snap-fit dan pengikat cepat lainnya, gunakan sekrup dan lem sebagai pengerat.

\subsection{Closed Loop System (Sistem Loop Tertutup)}

Sistem loop tertutup adalah sistem pengontrolan yang memiliki sifat sinyal pengeluaran dan mempunyai pengaruh pada reaksi pengontrolan komponen, sistem pengontrolan loop tertutup ini memiliki umpan balik yang sangat efisien, akan tetapi memiliki kesalahan penggerak, terbentuk perselisihan antara dua sinyal yaitu sinyal masukan dan sinyal umpan balik, perubahan sinyal pengeluaran atau fungsi sinyal turunan, diberikan kontroller untuk digunakan agar bisa memperkecil kesalahan (eror) untuk menghasilkan sinyal pengeluaran yang diinginkan. Seperti istilah Loop Tertutup, menggunakan reaksi umpan balik agar dapat 
memperkecil suatu kesalahan. Memberitahukan hubungan antara sinyal masukan dan sinyal keluaran dari metode sistem loop tertutup. Apabila dalam hal ini manusia bekerja sebagai server atau operator maka manusia pemegang software, jadi manusia akan memiliki sistem pengontrolan sinyal keluaran, agar sistem dalam keadaan yang stabil, seperti yang diinginkan, apabila terjadi perubahan dalam sistem loop tertutup maka manusia bertanggung jawab melakukan langkah-langkah pertama peraturan loop tertutup, agar dapat kembali pada keadaan sistem yang dinginkan oleh pengguna $[6,7]$.

\section{HASIL DAN PEMBAHASAN}

Alat ini nantinya akan menghasilkan cahaya laser yang dapat memberikan output seperti kaligrafi, ukiran, gambar, cutting. Mesin CNC Laser ini akan di rancang sesuai dengan apa yang ada pada skema wirring Gambar 1 dengan bantuan motor stepper maka laser akan bergerak dengan objek yang telah ditentukan sebelumnya melalui software, modul driver laser dan motor stepper dibuat dengan bantuan arduino nano yang digabungkan dengan modul motor stepper, penggerak motor stepper menggunakan servo driver [9].

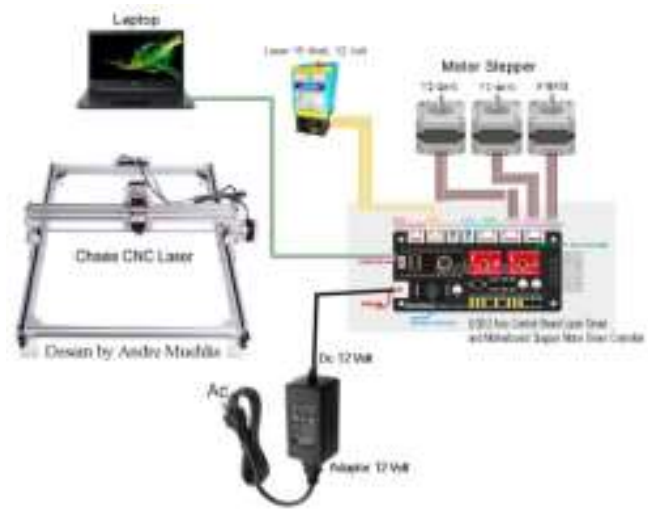

Gambar 1. Skema Wiring

Bagian-bagian pada Gambar 1 dapat dijelaskan sebagai berikut.

- Laptop sebagai perangkat hardware dalam mesin $C N C$, yang memberikan pengontrolan pada output mesin $C N C$.

- Chasis CNC, merupakan kerangka internal yang menjadi penyangga bagian-bagian alat elektronik.

- Laser Radiation Avoid 15 Watt sebagai penghasil cahaya yang menghasilkan engraver dan cutting.

- Motor stepper, sebagai penggerak laser ke arah X dan Y.

- $\quad$ CNC Shield sebagai pusat pengontrolan dari driver motor stepper dan laser.

- Adaptor $12 \mathrm{~V}$, memberikan tegangan DC ke CNC shield agar dapat di On/Off.
Diagram blok alat dapat dilihat pada Gambar 2.

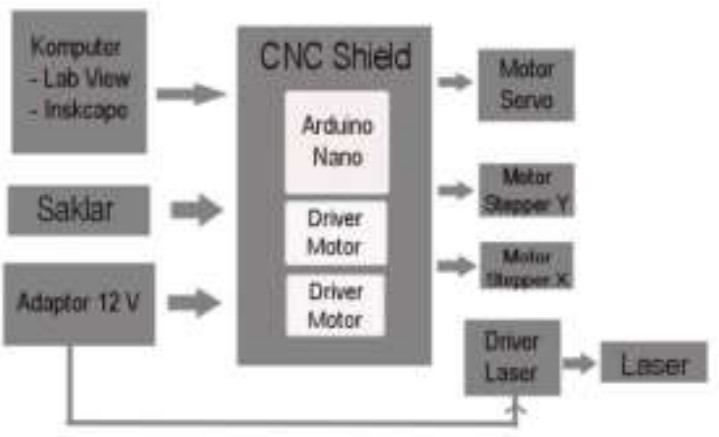

Gambar 2. Diagram Blok

Penjelasan masing-masing bagian pada Gambar 2 adalah sebagai berikut.

a. Komputer digunakan untuk memberikan pengontrolan pada arduino

b. Saklar sebagai On/Off dari CNC Shield.

c. Adaptor $12 \mathrm{~V}$ digunakan sebagai input DC dari AC.

d. CNC Shield sebagai pusat pengontrolan motor stepper dan laser.

e. Motor stepper sebagai roda penggerak laser.

f. Laser memancarkan sinar pada media yang ditentukan.

\subsection{Perangkat Lunak LASER GRBL}

Laser GRBL adalah perangkat lunak yang digunakan untuk mengontrol komponen dan menguji kinerja mesin CNC Engraver, cara penggunaannya membutuhkan komputer untuk memasukan perintah-perintah yang mengatur pergerakan axis $\mathrm{X}$ dan axis $\mathrm{Y}$ dengan cara mengatur putaran servo dan arah putaran motor stepper setiap axis $\mathrm{X}$ dan $\mathrm{Y}$ pada mesin laser Engraver pada perintah G-Code, Software GRBL yaitu sebuah aplikasi yang dapat mengunggah file $G$-Code ke Arduino, agar arduino dapat membaca perintah dalam bentuk $G$-Code. Software GRBL tersebut memudahkan para pengguna untuk memproses pemograman mesin laser Engraver pada sistem microcontroller yang digunakan pengguna. Tampilan Software Laser GRBL di perlihatkan pada gambar 3. Pada software ini bisa memberikan perintah secara langsung dari pengguna software [12].

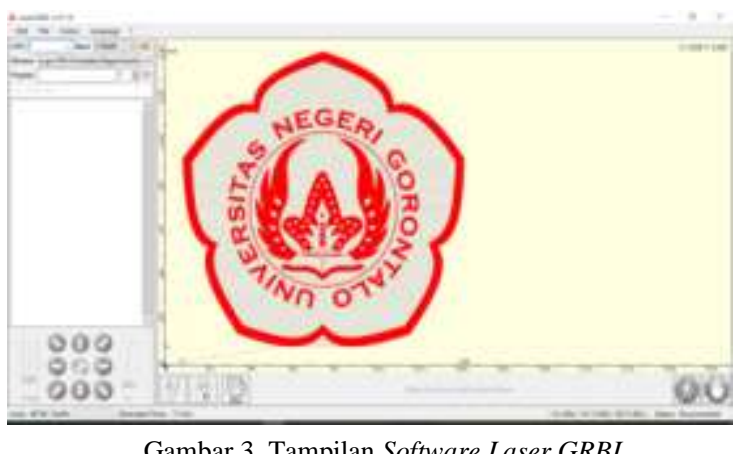

\subsection{Pengujian LaSeR}

Pengujian laser menggunakan laser diode 15 watt yang di sambungkan dengan arduino nano dalam bantuk $C N C$ shild, kemudian software GRBL mengirim $G$-Code ke arduino nano, arduino nano menerjemahkan hasil $G$-Code 
agar laser tersebut dapat memancarkan sinar sesuai yang diinginkan oleh pengguna. Pengujian laser dapat dilihat pada gambar 4.

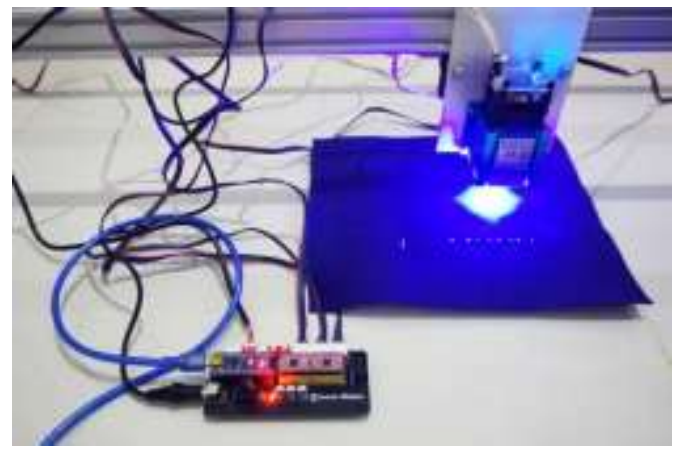

Gambar 4. Pengujian Laser Diode 15 Watt

\subsection{Hasil Pengujian Engraver Dan Cutting}

Pengujian laser engraver dengan software GRBL, pengujian dengan laser $15 \mathrm{~W}$ solid Wood engraver $100 \%$ daya laser, speed $3000 \mathrm{~mm} / \mathrm{min}$. ketebalan solid wood 2 $\mathrm{mm}$. Hasil pengujian engraver dapat dilihat pada gambar 5.

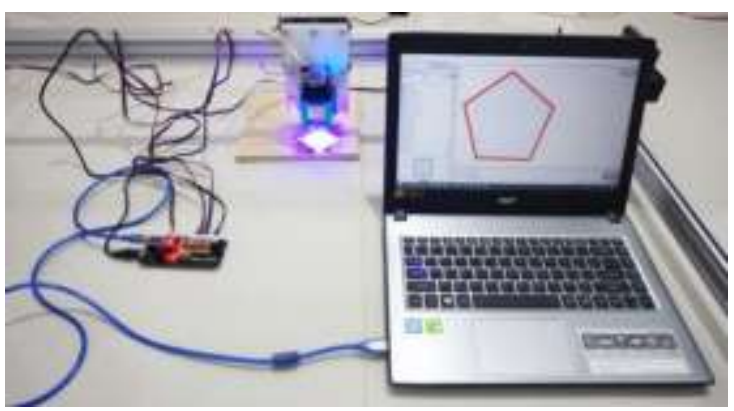

Gambar 5. Pengujian Solid Wood Engraver

Pengujian laser cutting dengan software GRBL, pengujian dengan laser $15 \mathrm{~W}$ Ply Wood engraver 100\% daya laser, speed $100 \mathrm{~mm} / \mathrm{min}$. ketebalan solid wood 3 $\mathrm{mm}$. Hasil pengujian cutting dapat dilihat pada gambar 6 .

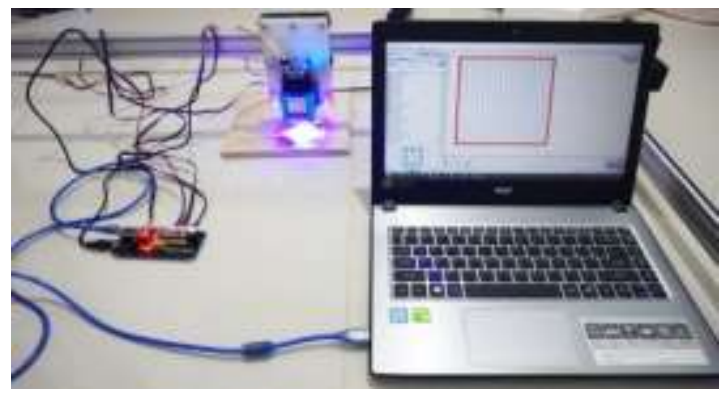

Gambar 6. Pengujian Ply Wood Cutting
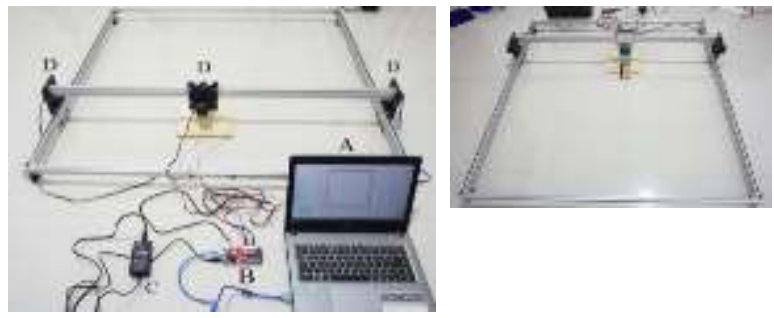

Gambar 7. Bentuk Keseluruhan Mesin $C N C$

Gambar 7 menunjukkan keseluruhan dari alat $C N C$. Secara keseluruhan terdapat 5 bagian yang dijelaskan sebagai berikut [11].

1. Bagian A, laptop yang berisikan software GRBL dimana sebuah data $G$-Code muncul dan dikirimkan ke arduino nano.

2. Bagian B, CNC Shild memiliki arduino nano, driver motor stepper, dan saklar, sebagai modul untuk $C N C$ laser.

3. Bagian $\mathrm{C}$, power supplay untuk menghidupkan modul/CNC Shild.

4. Bagian $\mathrm{D}$, motor stepper, roda penggerak, dan pambel, sebagai penggerak $\mathrm{X}$ dan $\mathrm{Y}$.

5. Bagian E, laser diode 15 watt sebagai cutting / engraver.

Tabel 1 memperlihatkan hasil pengujian mesin CNC yang telah dirancangbangun. Pengujian cutting dan engraving dilakukan pada material plywood.

Tabel I. Hasil Pengujian CNC Laser

\begin{tabular}{|c|c|c|c|}
\hline Material & Power/Speed & Size/Time & Pola \\
\hline $\begin{array}{l}\text { Plywood } 3 \\
\text { mm, } \\
\text { cutting }\end{array}$ & $\begin{array}{c}\text { Power laser } \\
100 \% \\
\text { Speed } 100 \\
\mathrm{~mm} / \mathrm{min}\end{array}$ & $\begin{array}{c}\text { Size } 100.3 \mathrm{x} \\
100.3 \mathrm{~mm} \\
\text { Time } 5 \text { hours, } 51 \\
\text { min }\end{array}$ & \\
\hline $\begin{array}{l}\text { Plywood } 3 \\
\text { mm, } \\
\text { engrave }\end{array}$ & $\begin{array}{c}\text { Power laser } \\
100 \% \\
\text { Speed } 3000 \\
\mathrm{~mm} / \mathrm{min}\end{array}$ & $\begin{array}{c}\text { Size } 100.3 \times 71.4 \\
\text { mm } \\
\text { Time } 1 \text { hours, } 33 \\
\text { min }\end{array}$ & \\
\hline $\begin{array}{l}\text { Plywood } 3 \\
\text { mm, } \\
\text { engrave }\end{array}$ & $\begin{array}{c}\text { Power laser } \\
100 \% \\
\text { Speed } 3000 \\
\mathrm{~mm} / \mathrm{min}\end{array}$ & $\begin{array}{c}\text { Size } 122.6 \mathrm{x} \\
100.4 \mathrm{~mm} \\
\text { Time } 11 \text { hours, } \\
38 \mathrm{~min}\end{array}$ & \\
\hline $\begin{array}{l}\text { Plywood } 1 \\
\text { mm, } \\
\text { engrave }\end{array}$ & $\begin{array}{c}\text { Power laser } \\
40 \% \\
\text { Speed } 3000 \\
\mathrm{~mm} / \mathrm{min}\end{array}$ & $\begin{array}{c}\text { Size } 100.6 \times 27.8 \\
\text { mm } \\
\text { Time } 1 \text { hours, } 8 \\
\text { min }\end{array}$ & \\
\hline $\begin{array}{l}\text { Material } \\
\text { Plywood } 1 \\
\text { mm, } \\
\text { cutting }\end{array}$ & $\begin{array}{c}\text { Power laser } \\
100 \% \\
\text { Speed } 200 \\
\mathrm{~mm} / \mathrm{min}\end{array}$ & $\begin{array}{c}\text { Size } 100.6 \mathrm{x} \\
100.6 \mathrm{~mm} \\
\text { Time } 1 \text { hours, } 58 \\
\text { min }\end{array}$ & \\
\hline
\end{tabular}




\section{KESIMPULAN}

Pada penelitian ini, Rancang bangun mesin CNC cutting/engraver telah berhasil diselesaikan. Software GRBL digunakan untuk mengirim G-Code ke Arduino Nano, selanjutnya Arduino menerjemahkan satu-persatu G-Code agar bisa mengontrol motor stepper dan laser $15 \mathrm{w}$. Mesin laser engraving dilengkapi dengan emergency stop, perangkat elektronika ini memiliki berfungsi untuk mengurangi kerusakan pada mesin $C N C$, apabila sistem mengalami kendali (error) dari pergerakan mesin yang membahayakan. Pengujian dilakukan pada material plywood $3 \mathrm{~mm}$ untuk cutting dan engraving dengan berbagai ukuran dan pola gambar. Dari hasil pengujian yang saya dapatkan bahwa mesin CNC Laser Engraver/Cutting dapat bekerja dengan hasil yang sangat baik dan sudah di uji pada lab elektronika jurusan teknik elektro.

\section{REFFERENSI}

[1] Eko Prianto, Herlambang Sigit Pramono. Proses Permesinan CNC Dalam Pembelajaran Simulasi CNC. Mei 2017, Jurnal Edukatif Elektro, Vol.1, No.1.

[2] Irawan Malik, Sairul Effendi, Soegeng Witjahjo, Rancang Bangun Mesin CNC Engraver Mini Sebagai Alat Bantu Pembelajaran, Juni 2019, Jurnal Teknika Vol. 13, No. 01

[3] Arief Irfan Syah Tjaja, Perancangan Memperbaiki Produk Smart Light Dengan Menggunakan Metode Design For Assembly
Boothroyd-Dewhurst, Jurusan Teknik Industri, Institut Teknologi Nasional.

[4] Corbettt, Dooner, Meleba dan Pym. Pembuatan assembling dan menganalisa desain yang ada pada komponen produk secara bersamaan.

[5] Rifki Ilyandi, Dodi Sofyan Arief, Tekad Indra Pradana Abidin. Menganalisis metode DFA untuk prototype pada mesin pemisah. Jurusan Teknik Mesin, Fakultas Teknik Universitas Riau.

[6] Ikhlash Syukran Harrizal1, Syafri, Adhy Prayitno. Perancangan sistem pengontrolan mesin $\mathrm{CNC}$ dengan menggunakan metode Closed Loop System. Jurusan Teknik Mesin, Universitas Riau.

[7] Marfanri Lamatenggo, Ifan Wiranto Prodi, Wrastawa Ridwan, Perancangan Balancing Robot Beroda Dua Dengan Metode Pengendali PID Berbasis Arduino Nano. Jambura Journal of Electrical and Electronics Engineering Vol. 2 No. 2, Juli 2020.

[8] Diki Muhamad Sobirin, Pembuatan Sistem Multi Computer Numerical Control (CNC) Pada Plotter Dan Laser CNC Engraving, Program Studi Teknik Elektro, Fakultas Teknik dan Ilmu Komputer, Universitas Komputer Indonesia. Volume 9, Nomor 1, April 2020.

[9] Didi Widya Utama, Perancangan Dan Analisis Rangka Mesin Desktop Cnc Milling, Program Studi Teknik Mesin Universitas Tarumanagara Jakarta, Volume 16 Nomor 1, Mei 2018.

[10] Karuniawan B. W, Anda Iviana Juniani. Optimasi Parameter Mesin Laser Cutting Terhadap Kekasaran Dan Laju Pemotongan Menggunakan Taguchi Grey Relational Analysis Method. Mei 2016. Rakasita R.

[11] Harist Fauzi. Rancang bangun sistem kontrol mesin laser dengan Arduino, Program Studi Teknik Mesin, Fakultas Teknik, President University.

[12] Muhammad Jufrizaldy, Ilyas, Marzuki. Rancang Bangun Mesin CNC Milling Menggunakan Sistem Kontrol GRBL Untuk Pembuatan Layout PCB. Februari 2020. Jurnal mesin sains terapan vol. 4 no. 1. 